\title{
A Single Doppler Shift of Laser Doppler for Measured Average Velocity
}

\author{
Adnan Salih ${ }^{1}$, Ali shukur Mahmood ${ }^{2}$ and Mariam Mohammed Abud ${ }^{3}$ \\ 1. Department of Physics, Collage of Sceinc for Women, University of Baghdad, Baghdad, Iraq \\ 2. Laser of Higher Education, University of Baghdad, Baghdad, Baghdad, Iraq \\ 3. Department of Physics, Collage of Education, University of Musstinserya, Baghdad, Iraq
}

Received: September 15, 2012 / Accepted: October 06, 2012 / Published: April 25, 2013.

\begin{abstract}
According test the results from samples of clinically normal for ages(20-59) and diabetes mellitusfor measure of blood concentration and resolved velocity by a single shift of laser Doppler flowmetry based on illuminated laser beam on the foot has been reported in this paper of patient safety and noninvasively. The main research to arrive a simple method noninvasive and get more information about the resolved velocity to diagnose the nature of disorder blood flow for different person by using low power laser source, coherent light without thermal effect upon living tissue.
\end{abstract}

Key words: Laser Doppler flowmetry, singleshift, RBC concentration, perfusion.

\section{Introduction}

Technique is based on measuring the Doppler shift induced by moving red cell, a noninvasive diagnostic method to measure blood flow in tissue. The blood cells to the illuminating coherent light.

The principle that is the basis for laser Doppler flowmetry (LDF) was first demonstrated by Forrester, et al. in 1955 [1], before the first working laser was presented. The theory was foremost developed by Forrester and extended by Cummins, et al. [2]. Laser Doppler perfusion monitoring was presented in 1989 [3], by Nilsson, et al. [4].

Until the beginning of the 1990s [5, 6], most of the improvements made in the field of LDF were foremost related to the hardware, including the development of laser Doppler perfusion imaging (LDPI). Since then, many of the improvements involve the signal analysis. For further references, a comprehensive review about methodological developments in LDF has recently been published by

Corresponding author: Adnan salih, doctor, research field: physics. E-mail: Dradnan_salih@yahoo.com.
Rajan, et al. at the Twenty group [7]. another method measurement of tissue blood flow provides essential contribution to the diagnosis of diseases which causes in impaired blood flow by non-invasive capillary blood flow measurement laser speckle and laser Doppler [8].

In this paper the laser Doppler flowmetry established a new method to measure blood flow on the dorsal plus in the foot to normal subject and diabetic mellitus patients results have been compared.

\section{Theories}

When light is scattered by a moving object it will be frequency shifted depending on the movement of the object, the direction of the incoming light and the direction of the scattered light with velocity $v(\mathrm{~m} / \mathrm{s})$. The angular frequency shift, $f_{D}$ will then be [9]:

$$
\begin{gathered}
f_{D}=(\text {-velocity of } R B C \cdot \text { Scattering vector })-v \cdot q= \\
-2 v / \lambda \sin \theta / 2 \cos \varphi
\end{gathered}
$$

where, $v$ is the velocity vector of the moving object in the plane of scattering, the scattering vector $q$ is the difference between the wave vectors $k_{i}$ and $k_{s}(|k|=$ 
$1 / \lambda)$ of the incident and scattered light wave, respectively, $\lambda$ is the wavelength, $\theta$ is the scattering angle, and $\varphi$ is the angle between $q$ and $v$ presented .The light wave incident to the particle has a frequency $f_{\mathrm{i}}$ and a wavelength $\lambda_{i}=1 / k_{\mathrm{i}}=c / f_{\mathrm{i}}$, where $c$ $=c_{0} / n$ is the speed of light in the tissue with refractive index $n$.

The frequency shift $f_{\mathrm{D}}$ is the difference between the frequency of the incident and scattered light waves, i.e. $f_{\mathrm{i}}=c / \lambda_{i}$ and $f_{\mathrm{s}}=c / \lambda_{\mathrm{s}}$, respectively.

$$
f_{D}=f_{i}-f_{s}=c\left(\frac{1}{\lambda_{i}}-\frac{1}{\lambda_{s}}\right)
$$

where the nominator is removed in the last step since $v$ $<c$. This observationalso leads to $\lambda_{\mathrm{i}} \approx \lambda_{s}$ and consequently $k_{i} \approx k_{s}$. This Doppler shift is dependent on the velocity of the moving red blood cells according equation:

$$
f_{D}=\frac{2 n v}{\lambda o} \times \sin \theta \cos \varphi
$$

where, $v$ is the velocity of the moving red blood cell, $\mathrm{n}$ is the refractive index of the medium with a diode laser $(\lambda=785 \mathrm{~nm})$, and the refractive index $n=1.4$ of skin tissue. according this equation can calculate the single Doppler shift by the for all different subjects and the velocity of blood cell.

$$
v=-f_{D} \times \frac{\lambda i}{2 n \sin \theta \cos \varphi}
$$

Subst. Eq. (1) into Eq. (3) can get as the resolved velocity.

To calculation of the RBC concentration and perfusion estimates Larsson has explained the expressions for the $\mathrm{RBC}$ concentration and perfusion estimates in the frequency domain. An alternative the time domain is given by Nilsson, et al. [10].

Let start by establishing a relationship between the red blood cell concentration $\mathrm{C}_{\mathrm{RBC}}$ and the fraction of Doppler-shifted photons $f$. A simple expiration by Beer-Lambert's low where the fraction non shifted photons can be approximated to Ref. [11]:

$$
1-f \approx \mathrm{e}^{-\mathrm{lp}(\mathrm{RBC}) \mu(\mathrm{RBCs})}
$$

where, $l_{p}$ is the photon path length in tissue $0.5 \mathrm{~mm}$ and $\mu_{S R B C}$ is the scattering coefficient for blood 222.

Perfusion $=$ Concentration of moving blood cells $\times$ Velocity of these cells.

Effect of glucose on absorption and scattering properties of Tissue-Glucose can affect the measured transmitted or reflected signal by absorption and scattering of light at $785 \mathrm{~nm}$ wavelength.

Attenuation of light in tissue is described, according to light transport theory, by the effective attenuation coefficient $\mu e f f$, which is explain in the following equation [12]:

$$
\begin{aligned}
\mu e f f & =\sqrt{3 \mu a\left(\mu a+\mu s^{\prime}\right)} \\
& =\sqrt{3 \mu a[\mu a+\mu s(1-g)}
\end{aligned}
$$

Fredriksson [13] put the model, this model consists of three layers; the bloodless epidermis layer with variable thickness and two dermis layers where the first layer is $0.5 \mathrm{~mm}$ thick and the second has an infinite thickness. The later research consider the structure of biological tissue is complex which is difficult to satisfy Mie calculation of phase function instead of used approximate empirical phase function (Table 1) appears the optical for laser diode $785 \mathrm{~nm}$. The most common phase function in bio-optics is the Henyey-Greenstein HG phase with different factors. To research in this field [9].

So depth Penetration sensitivity $1 / \mu$ eff is 0.5163977 $\mathrm{mm}$. The thickness (same scaling factor for all layers) and blood tissue fractions (concentrations) at three different flow velocities could be altered from the standard model.

All velocity components were evenly distributed between 0 and twice the mean velocity $(0.3,2.0)$.

Table 1 Optical properties of the tissue model.

\begin{tabular}{llllll}
\hline Tissue type & $n(-)$ & $\mu_{a}\left(\mathrm{~mm}^{-1}\right)$ & $\mu s^{\prime}\left(\mathrm{mm}^{-1}\right)$ & $\mu_{s}\left(\mathrm{~mm}^{-1}\right)$ & $g(-)$ \\
\hline Epidermis & 1.4 & 0.4 & 3.5 & 23 & 0.85 \\
Dermis & 1.4 & 0.1 & 2.0 & 13 & 0.85 \\
Subcutis & 1.4 & 0.1 & 2.0 & 13 & 0.85 \\
Blood & 1.4 & 0.5 & 2.0 & 222 & 0.991 \\
\hline
\end{tabular}




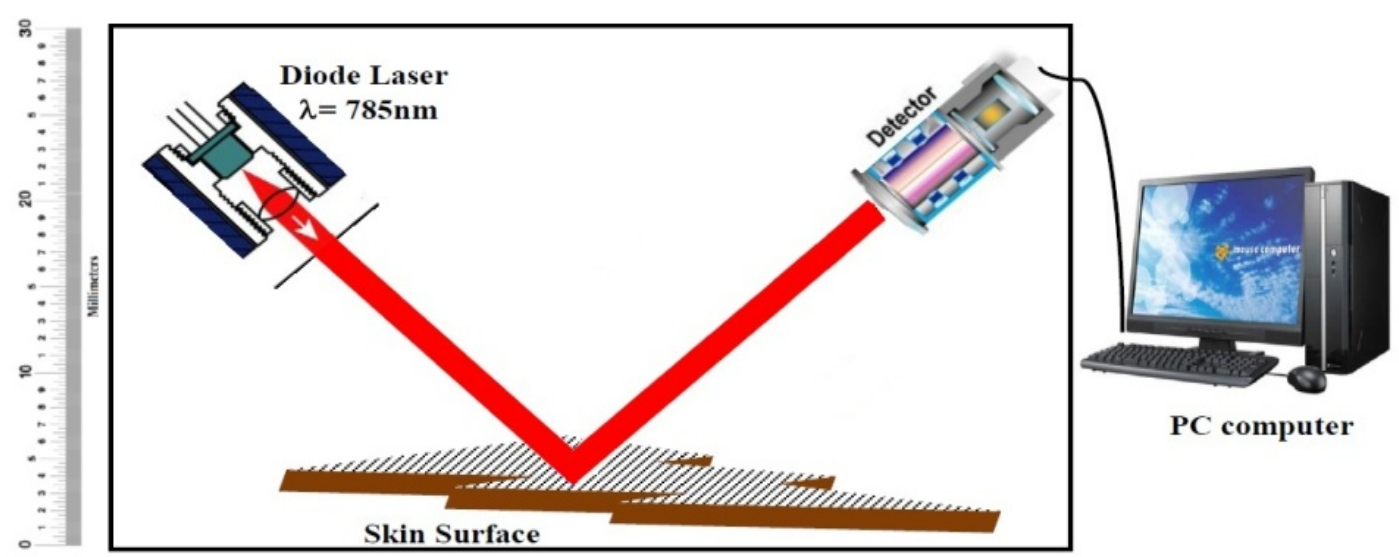

Fig. 1 Measuring arrangement for blood flow in microcirculation. A diode laser irradiates the skin and the remitted light is sampled by a photodiode without any optics.

\section{Material and Method}

This is study has been carried by research of the subject at different men ages, subjects having measurements (height, weight and some biochemical tests like blood glucose and hypertension).

A new method to laser Doppler flowmetry monitoring (LDFM) (Fig. 1) operation consist three parts: The light from a laser source(diode laser 785 $\mathrm{nm}, 30 \mathrm{mw}$ ) detector (the ocean optical spectrometer) and computer. When the light source is transmitted to the skin area $12.56 \mathrm{~mm}^{2}$. A portion of the back-scattered radiation is gathered by afferent optical fibers and detected in an operation set-up.

The system operate and record the incident wavelength output by software analysis on the screen at fitting line after the beak appearance and neglect the noises. Save results writes an ASCII file containing a list of the lines in the HR4000 software. All the test happened at room temperature of $25 \pm 1{ }^{\circ} \mathrm{C}$.

Subjects in the site position on the sitting of chair after get weight and height, put the foot on the position without movement and $0.5 \mathrm{~min}$ for acclimatization.

\section{Results and Discussion}

Initial experiment has carried on through the part of illuminated volume, this is hemisphere of radius about 2 $\mathrm{mm}$ incident on foot with wavelength $785 \mathrm{~nm}$ based on small Doppler shift for different subject is incident frequency $3.8216 \times 10^{14}$. The backscattered light is shifted of single wavelength, i.e., frequency accordingthe relation $f=\mathrm{c} / \lambda$, namely the original wave frequency and the Doppler shifted frequencies $\left(f_{D} \times\right.$ $\left.10^{11}\right)$.

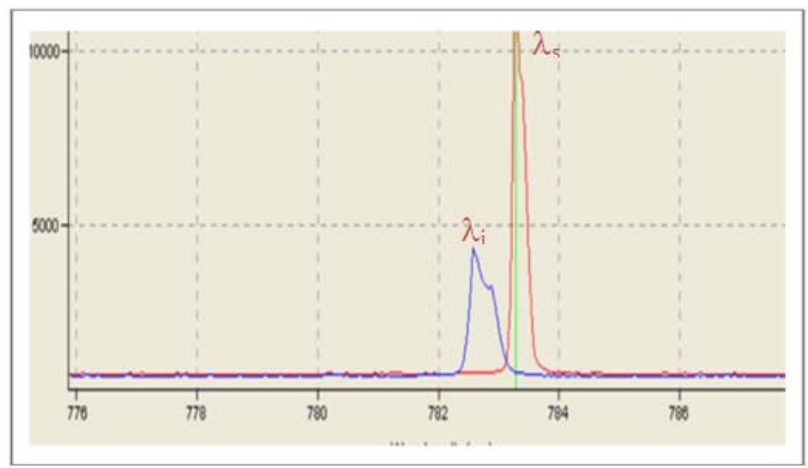

(a)

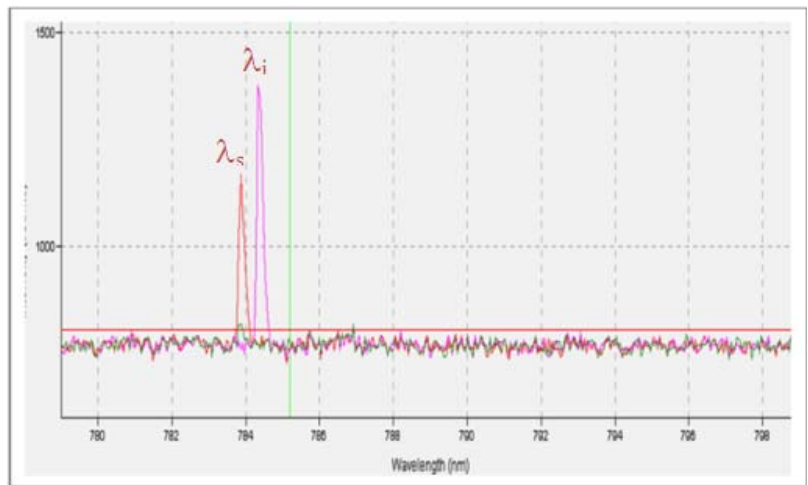

(b)

Fig. 2 Show the peak of incidence light and scattering light for (a) normal subject ages 24 and (b) Diabetes patients (DM) ages 24 year patient the opposite side from clinically normal. 
Table 2 Subject demographics for Clinically normal.

\begin{tabular}{|c|c|c|c|c|c|c|c|c|c|}
\hline No. & Gender & $\begin{array}{l}\text { Age } \\
\text { (year) }\end{array}$ & $\begin{array}{l}\text { Height } \\
(\mathrm{m})\end{array}$ & $\begin{array}{l}\text { Weight } \\
(\mathrm{kg})\end{array}$ & $\begin{array}{l}\text { BMI } \\
\left(\mathrm{Kg} / \mathrm{m}^{2}\right)\end{array}$ & $\begin{array}{l}f d \times 10^{11} \\
(\mathrm{~Hz})\end{array}$ & $\mathrm{V}(\mathrm{mm} / \mathrm{s})$ & $\begin{array}{l}\text { CRBC } \\
\times 10^{-6} \\
\end{array}$ & $\begin{array}{l}\text { Perfusion } \\
(\mathrm{PU})=\mu \mathrm{m} / \mathrm{s}\end{array}$ \\
\hline 1 & Male & 20 & 1.801 & 61.2 & 18.8679 & 6.6018 & 1.2008 & 15.32835 & 0.01840628 \\
\hline 2 & Female & 21 & 1.65 & 53.5 & 19.65106 & 6.6018 & 1.2008 & 15.32835 & 0.01840628 \\
\hline 3 & Male & 22 & 1.825 & 90.7 & 27.23212 & 6.6018 & 1.2008 & 15.32835 & 0.01840628 \\
\hline 4 & Male & 23 & 1.803 & 80.6 & 24.7938 & 3.5727 & 0.6482 & 8.385799 & 0.0054356 \\
\hline 5 & Male & 24 & 1.691 & 82.4 & 28.8164 & 3.8171 & 0.69428 & 8.959769 & 0.00622 \\
\hline 6 & Male & 25 & 1.73 & 88.9 & 29.7036 & 0 & 0 & 0 & 0 \\
\hline 7 & Female & 27 & 1.535 & 55.2 & 23.4273 & 3.3282 & 0.60535 & 7.811663 & 0.00472879 \\
\hline 8 & Male & 28 & 1.77 & 67 & 21.3859 & 2.9782 & 0.54239 & 6.989918 & 0.00379126 \\
\hline 9 & Female & 29 & 1.47 & 55.6 & 25.73 & 3.5727 & 0.6482 & 8.385799 & 0.0054356 \\
\hline 10 & Male & 30 & 1.7 & 72.9 & 25.2249 & 3.5727 & 0.6482 & 8.385799 & 0.0054356 \\
\hline 11 & Male & 33 & 1.79 & 74.8 & 23.3451 & 3.5727 & 0.6482 & 8.385799 & 0.0054356 \\
\hline 12 & Male & 34 & 1.69 & 78 & 27.31 & 3.5727 & 0.6482 & 8.385799 & 0.0054356 \\
\hline 13 & Male & 35 & 1.772 & 105.9 & 33.7263 & 6.6018 & 1.2008 & 15.32835 & 0.01840628 \\
\hline 14 & Male & 36 & 1.86 & 95.5 & 27.6043 & 2.9782 & 0.54239 & 6.989918 & 0.00379126 \\
\hline 15 & Male & 37 & 1.66 & 80 & 29.03178 & 6.3577 & 0.8376 & 14.92814 & 0.012508 \\
\hline 16 & Female & 38 & 1.62 & 91.3 & 34.7889 & 3.5727 & 0.6482 & 8.385799 & 0.0054356 \\
\hline 17 & Female & 40 & 1.68 & 96.4 & 34.1553 & 3.3282 & 0.60535 & 7.811663 & 0.00472879 \\
\hline 18 & Male & 41 & 1.81 & 96.3 & 29.3947 & 3.5727 & 0.6482 & 8.385799 & 0.0054356 \\
\hline 19 & Male & 42 & 1.77 & 106.3 & 33.93 & 3.5727 & 0.6482 & 8.385799 & 0.0054356 \\
\hline 20 & Male & 43 & 1.763 & 74.9 & 24.09778 & 3.5727 & 0.6482 & 8.385799 & 0.0054356 \\
\hline 21 & Male & 52 & 1.68 & 76.7 & 27.17545 & 0.4891 & 0.089028 & 8.385799 & 0.000102172 \\
\hline 22 & Male & 55 & 1.69 & 98.8 & 29.00519 & 2.9782 & 0.54239 & 1.14764 & 0.00379126 \\
\hline 23 & Male & 59 & 1.7 & 81.2 & 28.09688 & 3.3282 & 0.6535 & 6.989918 & 0.00510487 \\
\hline
\end{tabular}

Table 3 Subject demographics for DM diseased subjects.

\begin{tabular}{|c|c|c|c|c|c|c|c|c|c|c|c|}
\hline NO. & Gender & $\begin{array}{l}\text { Age } \\
\text { (year) }\end{array}$ & $\begin{array}{l}\text { Height } \\
\text { (m) }\end{array}$ & $\begin{array}{l}\text { Weight } \\
(\mathrm{kg})\end{array}$ & $\begin{array}{l}\text { BMI } \\
\left(\mathrm{Kg} / \mathrm{m}^{2}\right)\end{array}$ & $\begin{array}{l}f d \times 10^{11} \\
(\mathrm{~Hz})\end{array}$ & $V(\mathrm{~mm} / \mathrm{s})$ & $\begin{array}{l}\text { CRBC } \\
\times 10^{-6}\end{array}$ & $\begin{array}{l}\text { Perfusion } \\
(\mathrm{PU})=\mu \mathrm{m} / \mathrm{s}\end{array}$ & $\begin{array}{l}\text { glucose } \\
\mathrm{mg} / \mathrm{dl}\end{array}$ & $\begin{array}{l}\text { duration } \\
\text { time }\end{array}$ \\
\hline 1 & Female & 20 & 1.56 & 55 & 22.6003 & -2.679 & -0.4888 & -6.28417 & 0.003072 & 133 & 1year \\
\hline 2 & Female & 21 & 1.5 & 57 & 25.3333 & -2.6795 & -0.4888 & -6.28417 & 0.003072 & 130 & 2 year \\
\hline 3 & Male & 23 & 1.73 & 89.2 & 29.8039 & -1.9065 & -0.3472 & -4.47186 & 0.0015577 & 126 & 4 month \\
\hline 4 & Male & 24 & 1.746 & 70 & 22.962 & -2.6873 & -0.3546 & -6.3024 & 0.000107 & 265 & 2 year \\
\hline 5 & Female & 25 & 1.503 & 120 & 53.12063 & -5.517 & -0.7292 & -12.9341 & 0.009436 & 367 & 4 year \\
\hline 6 & Male & 26 & 1.68 & 71.8 & 25.4393 & -3.9076 & -0.7121 & -9.0045 & 0.006412 & 278 & 8 year \\
\hline 7 & Female & 28 & 1.6 & 58 & 22.65625 & -3.2274 & -0.4577 & -7.24663 & 0.003085 & 160 & 20 year \\
\hline 8 & Female & 28 & 1.603 & 66.1 & 25.72375 & -3.1241 & -0.5587 & -7.32649 & 0.0040938 & 168 & 10 year \\
\hline 9 & Male & 32 & 1.712 & 87.2 & 29.75150 & -3.609 & -0.6454 & -8.463 & 0.0054625 & 220 & 14 year \\
\hline 10 & Male & 35 & 1.7 & 74.6 & 25.81314 & -3.5596 & -0.6366 & -8.34737 & 0.0053144 & 189 & 10 year \\
\hline 11 & Male & 37 & 1.9 & 105 & 29.0858 & -3.9488 & -0.5218 & -9.25971 & 0.004832 & 231 & 4 year \\
\hline 12 & Male & 38 & 1.735 & 100 & 33.22010 & -3.1241 & -0.412 & -7.32647 & 0.003025 & 317 & 8 year \\
\hline 13 & Male & 40 & 1.77 & 85.3 & $27.2271 \mathrm{t}$ & -2.7780 & -0.3671 & -6.51516 & 0.002398 & 132 & 4 year \\
\hline 14 & Female & 41 & 1.53 & 74.5 & 31.82536 & -2.635 & -0.4714 & -6.18218 & 0.0029146 & 181 & 12 year \\
\hline 15 & Male & 42 & 1.599 & 72 & 28.16018 & -2.586 & -0.4625 & -6.06492 & 0.0025 & 328 & 8 year \\
\hline 16 & Female & 43 & 1.632 & 87 & 32.66472 & -3.1241 & -0.5587 & -7.32649 & 0.0040938 & 164 & 5 year \\
\hline 17 & Male & 45 & 1.87 & 97.4 & 27.85324 & -7.8364 & -1.0337 & -1.83663 & 0.0189795 & 389 & 0.25 year \\
\hline 18 & Female & 46 & 1.714 & 79.1 & 26.92494 & -3.075 & -0.5499 & -7.32584 & 0.0040291 & 245 & 13 year \\
\hline 19 & Male & 47 & 1.904 & 77.4 & 21.35045 & -2.6359 & -0.3483 & -6.18218 & 0.0021537 & 238 & 5 year \\
\hline 20 & Female & 50 & 1.703 & 78.4 & 27.03253 & -1.266 & -0.1673 & -2.96966 & 0.0004968 & 136 & 15 year \\
\hline 21 & Male & 51 & 1.735 & 100 & 33.22010 & -3.4607 & -0.457 & -8.115 & 0.0037118 & 111 & 5 year \\
\hline 22 & Female & 53 & 1.702 & 88.9 & 30.68894 & -2.6359 & -0.4714 & -6.18218 & 0.0029146 & 170 & 17 year \\
\hline 23 & Male & 54 & 1.713 & 66.7 & 22.73061 & -1.122 & -0.2935 & -2.63193 & 0.0007727 & 324 & 12 year \\
\hline 24 & Male & 55 & 1.582 & 64.5 & 25.77191 & -3.316 & -0.6020 & -7.89353 & 0.0047521 & 361 & 14 year \\
\hline 25 & Male & 57 & 1.69 & 77.9 & 27.27495 & -3.0731 & -0.4059 & -7.20693 & 0.0029253 & 208 & 4 year \\
\hline 26 & Female & 58 & 1.405 & 75 & 37.99343 & -2.8800 & -0.5151 & -6.80920 & 0.0035075 & 167 & 20 year \\
\hline 27 & Female & 59 & 1.81 & 87.3 & 26.64753 & -2.586 & -0.3793 & -6.04958 & 0.002072 & 318 & 23 year \\
\hline
\end{tabular}




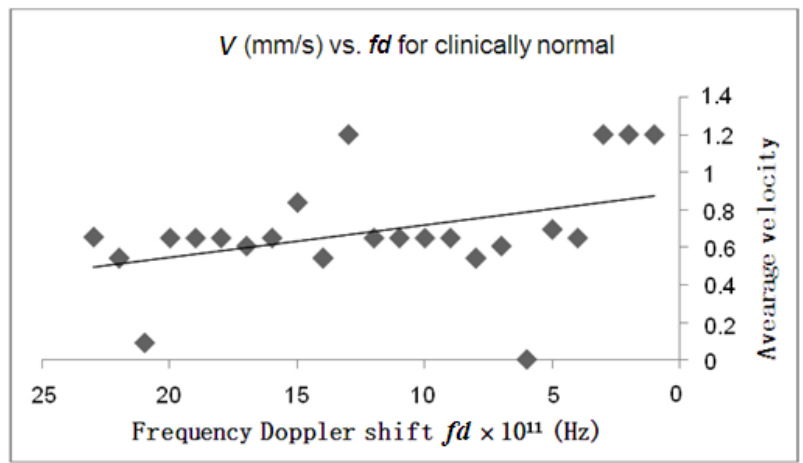

(a)

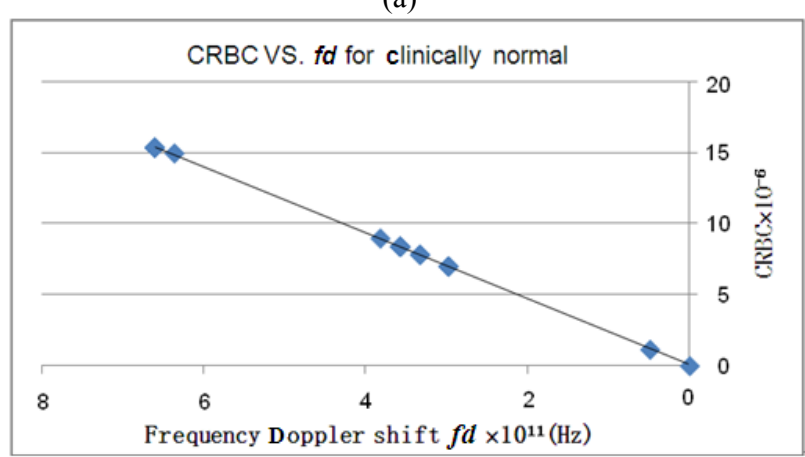

(b)

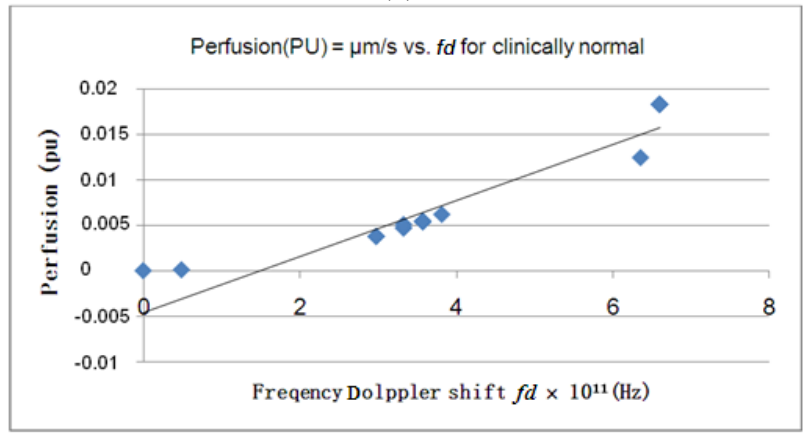

(c)

Fig. 3 Explain the relation (a) average blood flow (b) Concentration red blood cell (c) perfusion with frequency Doppler shift for normal subject.

Fig. 2 shows the peak of incidence light and scattering light for different subjects.

The LDFM for diseased subject resolved velocities $<1 \mathrm{~mm} / \mathrm{s}$. the lower velocities of all diseases and concentration red blood cell but higher perfusion about 0.10409 for high level glucose. The increased blood flow occurs in vessels with a velocity above $1 \mathrm{~mm} / \mathrm{s}$. This results is satisfy with Fredriksson, et al. [14].

The perfusion of diseases is higher than the clinically normal but the concentration of red blood cell is lower than normal subjects. A significantly total

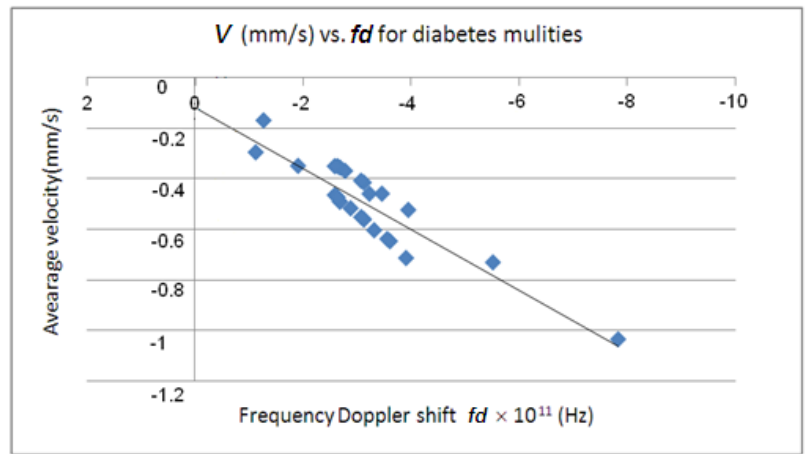

(a)

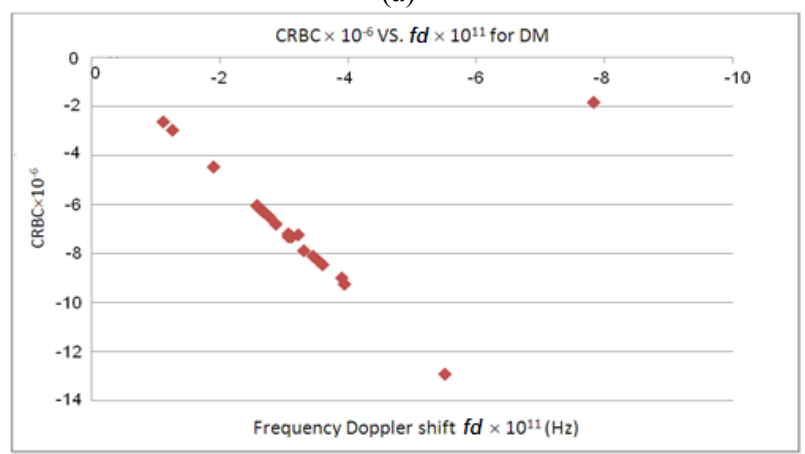

(b)

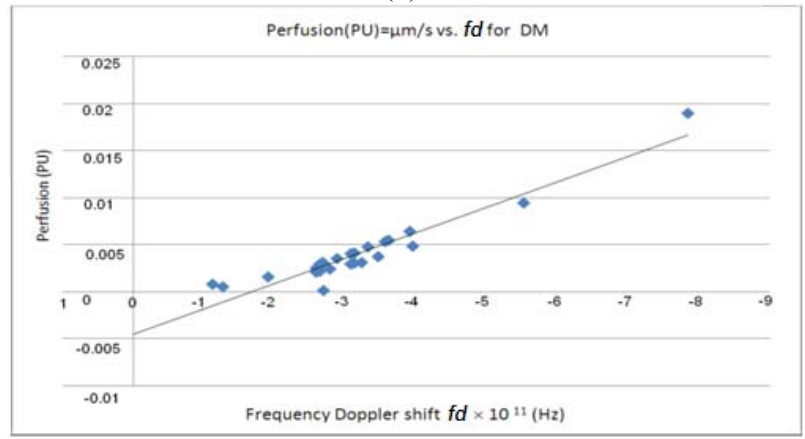

(c)

Fig. 4 Explain the relation (a) average blood flow (b) Concentration red blood cell (c) perfusion with frequency Doppler shift for diabetes Mellitus subjects.

perfusion $0.4<v<1.2008$. The sign $(-)$ indicate the resolved velocity opposite direction to the normal subject. Total perfusion is higher unless the disease with insulin is lower perfusion.

\section{Conclusions}

The perfusion increases occur in the hyperglycemia and high level glucose for patients so that increases the velocity to baseline data of normal subject indicated a distribution of flow to higher velocity region of capillaries vessels regions compare to the 
mean blood velocity for various types of vessels [13]. All subjects microvascular abnormality has also been increased flow through the arteriovenous shunts resulting in reduced capillary flow less than $0.3 \mathrm{~mm} / \mathrm{s}$ in Table 2 for normal subject and Table 3 for diseases. While differences in blood flow between DM and controls using laser Doppler flowmetry studies have reported a lower blood flow in diabetes mellitus at different glucose compared with controls indicates the opposite scattering causes in all states.

The perfusion measure is divided into two region $v$ $<1 \mathrm{~mm} / \mathrm{s}, v>1 \mathrm{~mm} / \mathrm{s}$. the method presented is based on a single Doppler shift to measured spectra at the same separation between source-detector. The diabetes mellitus indicates to distribution of velocities appears to distribution of level glucose the decreases velocity causes increasing perfusion significant difference between the DM patient and normal subjects is found in the two lowest velocity regions.

\section{References}

[1] A.T. Forrester, Photoelectric mixing as a spectroscopic tool, Journal of the Optical Society of America 51 (3) (1961) 253-259.

[2] H.Z. Cummins, H.L. Swinney, Light Beating Spectroscopy, in Progress in Optics, E. Wolf, North-Holland, 1970, pp. 135-200,

[3] G.E. Nilsson, T. Tenland, P.A. Oberg, Evaluation of a laser Doppler flowmeter for measurement of tissue blood flow, IEEE Transactions on Biomedical Engineering 27 (10) (1980) 597-604.

[4] G.E. Nilsson, A. Jakobsson, K. Wardell, Imaging of tissue blood flow by coherent light scattering, in:
Proceedings of the Annual International Conference of the IEEE Engineering, 1989, pp. 2097-2107.

[5] G.E. Nilsson, Signal processor for laser Doppler tissue flowmeters, Medical and Biological Engineering and Computing 22 (4) (1984) 343-348.

[6] T.J.H. Essex, P.O. Byrne, A LASER Doppler scanner for imaging blood-flow in skin, Journal of Biomedical Engineering 13 (3) (1991) 189-194.

[7] V. Rajan, B. Varghese, T.G. Van Leeuwen, W. Steenbergen, Review of methodological developments in laser Doppler flowmetry, Lasers in Medical Science 24 (2) (2009) 269-283.

[8] A.K. Jayanthy, N. Sujatha, M.R. Eddy, Non-invasive capillary blood flow measurement: Laser speckle and laser Doppler, World Academy of Science, Engineering and Technology 77 (2011) 1007-1012.

[9] I. Fredriksson, M. Larsson, T. Stromberg, Forced detection Monte Carlo algorithms for accelerated blood vessel image simulations, Journal of Biophotonics 3 (2) (2009) 178-184.

[10] R.F. Bonner, R. Nossal, Model for laser Doppler measurements of blood flow in tissue, Appl. Opt. 20 (1981) 2097-2107.

[11] I. Fredriksson, C. Fors, J. Johansson, Laser Doppler flowmetry: Atheoretical framework, Department of Biomedical Engineering, Linköping University, 2007.

[12] B.J. Berne, R. Pecora, Dynamic Light Scattering, Wiely, New York, 1976, pp. 137-139.

[13] I. Fredriksson, Quantitative laser Doppler flowmetry, 1 inkoping studies in science and technology, Ph.D. Thesis, Department of Biomedical .Engineering Linkoping University, Sweden, 2009.

[14] I. Fredriksson, M. Larsson, F. Nyström, T. Länne, C.J. Östgren, T, Strömberg, Reduced arteriovenous shunting capacity after local heating and redistribution of baseline skin blood flow in type 2 diabetes assessed with velocity-resolved quantitative laser Doppler flowmetry, Department of Biomedical Engineering, Linköping University, Sweden, 2012. 